\title{
TRABALHO DOCENTE: UMA CATEGORIA ONTOLÓGICA
}

\author{
José Luís Vieira de Almeida ${ }^{1}$
}

\begin{abstract}
RESUMO
O objetivo geral do trabalho que permitiu a elaboração deste texto é compreender as mediações que se estabelecem entre docentes e estudantes como constituintes do trabalho docente. Trata-se de um trabalho de cunho teórico e bibliográfico. Discute-se, em primeiro lugar, o trabalho compreendendo-o como uma mediação. Em seguida, examina-se a mediação com base nas filosofias de Hegel, Marx, Lukács e Mészáros, portanto, numa perspectiva dialética. Inicia-se o exame da categoria em Hegel que a desenvolveu, passandose, em seguida, a discuti-la em Marx que a compreendeu na perspectiva da Ontologia do Ser Social. Os outros autores a abordaram visando a análise do referencial marxista. Na segunda parte do texto, aborda-se a mediação como categoria ontológica e como referência para compreender o trabalho docente. Conclui-se o texto discutindo-se as possibilidades de desenvolvimento dessa perspectiva teórica como práxis na sala de aula e destacando-se a necessidade de compreender a categoria trabalho docente como uma mediação ontológica.
\end{abstract}

Palavras-chave: Trabalho docente; mediação; ontologia do ser social.

\section{INTRODUÇÃO}

Neste texto, discute-se, em primeiro lugar, o trabalho, compreendendo-o como uma mediação. Em seguida, examina-se a mediação com base nas filosofias de Hegel por meio do texto de Garaudy (1983), Marx por meio dos escritos Lefebvre (1979 e 1983). Examinam-se também as formulações de Lukács (1979 e 1982) e Mészáros (1981). Inicia-se a discussão da categoria em Hegel que a desenvolveu, passando-se, em seguida, a discuti-la em Marx que a compreendeu na perspectiva da Ontologia do Ser Social. Os outros autores a abordaram visando a análise do referencial marxista.

$\mathrm{Na}$ segunda parte do texto, aborda-se a mediação como categoria ontológica e como referência para compreender o trabalho docente.

Conclui-se o texto discutindo-se as possibilidades de desenvolvimento dessa perspectiva teórica como práxis na sala de aula e destacando-se a necessidade de compreender a categoria trabalho docente como uma mediação ontológica.

\footnotetext{
${ }^{1}$ Departamento de Educação - IBILCE - Universidade Estadual Paulista - São José do Rio Preto SP. E- mail: joseluisv@terra.com.br
} 
Como o enfoque apresentado neste texto não é usual na área da educação, considerase importante mostrar as diferenças entre uma abordagem epistemológica e uma abordagem ontológica. A epistemologia tem por base a relação entre o sujeito cognoscente e o objeto a conhecer-se. Já a Ontologia do Ser Social está fundada na relação entre dois ou mais seres sociais que, no caso da prática educativa, buscam ensinar ou aprender. Em uma relação ontológica, eles não podem ensinar e aprender ao mesmo tempo, porque nessa perspectiva não se desenvolve a tensão dialética que é vital na Ontologia do Ser Social. A diferença principal entre a epistemologia e esta Ontologia será explicada quando a categoria mediação for discutida.

Antes de iniciar-se a discussão, é necessário esclarecer que para Marx a epistemologia, a ontologia e a lógica têm igual peso, ou seja, uma não é mais importante ou mais fundamental que as outras. Por isso, o que se pretende neste texto é, somente, evidenciar o caráter ontológico da relação educativa, sem, por isso, minimizar a importância da lógica e da epistemologia.

\section{A MEDIAÇÃo}

O uso do vocábulo "mediação" tem sido freqüente entre os pesquisadores do campo da educação no nosso país, e esta freqüência é diretamente proporcional à imprecisão dos sentidos que ele assume. A palavra mediação pode se referir ao termo médio de uma relação entre termos eqüidistantes, ou à ligação entre dois termos distintos, ou ainda à passagem de um termo a outro. Ela pode também dizer respeito à harmonização de conflitos entre partes ou interesses antagônicos. Fala-se, por exemplo, no papel do professor enquanto mediador da relação ensino-aprendizagem, ou do caráter mediador presente na relação entre o conhecimento sistematizado pelas ciências naturais ou humanas e aquele que o aluno desenvolve no seu cotidiano. Assim, atribui-se à mediação, o dever ou a possibilidade de igualar os termos (ensino e aprendizagem ou conhecimento sistemático e experiência cotidiana, ou ainda professor e aluno), dissolvendo as diferenças entre eles.

A mediação é geralmente considerada como o produto de uma relação entre dois termos opostos que, por meio dela, podem ser homogeneizados, e esta homogeneização implica equilíbrio entre ambos e assim, eles deixam de ser opostos. Quando se compreende a mediação como o resultado, como um produto, a necessária relação entre dois termos se reduz à soma de ambos, o que resulta na sua anulação mútua, levando-os ao ponto de equilíbrio. Esta idéia concebe a mediação como o resultado da aproximação entre dois termos que, 
embora distintos no início, quando totalmente separados, tendem a igualar-se à medida que se aproximam.

A mediação é uma categoria filosófica que alcança o seu pleno desenvolvimento em Hegel e, portanto, ela é dialética e não pode ser entendida fora da perspectiva deste método de análise. Cabe então advertir, desde logo, que a mediação não pode ser considerada como um produto, pois esta noção não tem lugar na dialética; ela aceita apenas a idéia de processo, que se pauta nas concepções de força e de movimento.

O termo mediação, na filosofia de Hegel, diz respeito à relação entre o imediato e o mediato. Ela é, portanto, uma força negativa que une o imediato ao mediato e, por isso, também os separa e os distingue. Apesar de propiciar a passagem de um termo a outro, pela superação do imediato no mediato, ela não é apenas uma simples via de ligação, uma "ponte" entre os dois pólos, ela é um dos termos da relação responsável por viabilizá-la. A mediação permite, por meio da negação, que o imediato seja superado no mediato sem que o primeiro seja anulado ou suprimido pelo segundo, ao contrário, o imediato está presente no mediato, e este está presente naquele. O mediato não supera o imediato, quem o faz é a mediação, assim, a força inerente à superação não se manifesta nos pólos da relação, o imediato e o mediato, ela é uma propriedade da mediação.

Conforme Garaudy (1983), a superação do imediato ocorre na mediação; o mediato é, então, o estado que dela resulta. A superação se viabiliza só quando coisas ou estados distintos estabelecem relações entre si, mas elas devem ser de mediação, que é uma relação qualitativa fundada na força e caracterizada pela negatividade e pelo reflexo. Quando se trata da superação, se deve ter claro que ela sempre se refere a uma contradição. Por isso, se a superação ocorre na mediação, a contradição também se manifesta nela. Assim, não se pode buscá-las nas coisas, mas nas relações de mediação que elas mantêm entre si.

A passagem de uma coisa a outra ou de um estado a outro por meio da superação não suprime a coisa ou o estado superados, ao contrário, os incorpora a aqueles que os superaram. Eles não são suprimidos, porque também contribuem no processo de superação. A mediação na qual ocorre a superação não é unilateral nem excludente, busca a totalidade e, assim, combate a unilateralidade da parte sem exclui-la do todo e, ao mesmo tempo, sem diluí-la nele.

Até aqui, a mediação foi discutida como superação do imediato no mediato. O acento nesta lógica permite o entendimento das categorias do método dialético que fundamentam a mediação: o movimento, a força e a negatividade. Cabe agora discuti-la como categoria 
ontológica pelo exame de algumas das suas expressões possíveis, a sua dinâmica, e como ela ocorre.

A mediação é uma categoria ontológica fundada na Ontologia do Ser Social e só pode ser compreendida como tal porque, ela é a responsável pela humanização do ser humano. Essa afirmação se esclarece quando se compreende que o radical onthos é o mesmo que Ser. Assim, ontologia é a teoria do Ser. Ela é distinta da epistemologia, porque esta é a teoria do conhecimento. Os limites deste texto permitem explicar apenas a principal diferença entre as duas. O Ser é concreto e, por isso, não pode ser dividido; o conhecimento, por outro lado, é abstrato e, por isso, precisa ser dividido para ser compreendido. A relação ontológica, baseada na Ontologia do Ser Social, se estabelece entre a natureza como Ser, portanto concreta (total), e o Ser Humano concreto (total). Ela pode estabelecer-se também entre os seres humanos.

A relação epistemológica, ao contrário, só pode ser estabelecida entre o sujeito cognoscente e o objeto do conhecimento. Este objeto deve, necessariamente, ser uma pequena parte do todo, portanto ele resulta de uma abstração². A epistemologia é fundamental na produção do conhecimento, pois ele só pode ser produzido por meio das relações epistemológicas. Em outros termos, não há como produzir conhecimento a partir da ontologia, mesmo quando se trata da Ontologia do Ser Social.

Feita essa distinção, pode-se agora retomar o exame da mediação como categoria ontológica, tomando-se como ponto de partida a sua compreensão no pensamento marxiano. Talvez o modo mais adequado para explicar a mediação seja aquele usado por Marx: "A fome é fome, mas a fome que se satisfaz com carne cozida, que se come com faca e garfo, é uma fome muito distinta da que devora carne crua, com unhas e dentes”. (MARX, Introdução de 1857 apud LUKÁCS, 1979, p. 68). Assim, a fome animal está no plano do imediato, no qual vivem todos os seres vivos; já a fome humana é mediata, porque satisfeita com base em mediações: o tempero e o cozimento da carne, o garfo e a faca. Além disso, foi preciso acender o fogo e arrumar a mesa. A fome humana quando é sentida também é imediata, mas não é satisfeita nesse plano. Ainda com base na explicação de Marx, pode-se reiterar que apenas os seres humanos são capazes de mediar.

\footnotetext{
2 Sobre a relação dialética entre o abstrato e o concreto consultar: Kosik, k. Dialética do Concreto. Tradução de Célia Neves e Alderico Turibio, 2. ed., Rio de Janeiro, Paz e Terra, 1976.(Coleção rumos da cultura moderna, v. 26).
} 
A mediação em Marx pode expressar-se no trabalho e na práxis. Nessa perspectiva, o trabalho é o resultado da tensão dialética entre a natureza imediata e o ser humano que é mediato. Por meio desta tensão, o ser humano supera a natureza quando a transforma.

O trabalho é a categoria central do pensamento de Marx não apenas porque ele constitui a base material dos modos de produção e o autor examinou, em profundidade, o modo de produção capitalista, mas, sobretudo, porque esta categoria é a base da Ontologia do Ser Social.

O fundamento desta ontologia é a humanização do ser humano. Esta afirmação seria redundante caso a humanidade fosse compreenda como inata a ele. A humanidade é decorrente do processo de humanização que é histórico. Assim o ser humano pode tanto humanizar-se como desumanizar-se. Para a Ontologia do Ser Social, o trabalho, quando não alienado, promove a humanização do ser humano porque o distingue da natureza ao torná-lo capaz de transformá-la.

Como já se afirmou, a mediação tem por base o movimento e a negatividade. Assim, no trabalho que é movimento (relação dialética entre o ser humano e a natureza), o ser humano nega a natureza, e a natureza nega o ser humano. Nesse processo, tanto a natureza quanto o ser humano são superados pelo trabalho. É importante ressaltar que, do ponto de vista da dialética marxiana o ser humano nunca deixa de ser natural, pois ele exprime a sua natureza humana.

A práxis é também uma relação ontológica desenvolvida por Marx. Ela expressa a tensão entre a Prática e a Teoria. A tensão entre a primeira imediata e a segunda mediata gera a práxis que supera a ambas. É importante esclarecer que a mediação supera o imediato e o mediato presentes na relação, mas esta superação se dá no plano do mediato, um outro estado mediato, que é diferente daquele primeiro. Em outros termos, na relação de mediação, o mediato modifica o imediato, contudo também é modificado por ele. Por isso, os dois são superados, ainda que essa superação ocorra no mediato.

Outro modo de compreender as relações de mediação é aquele apresentado por Lukács (1982). Para ele, a mediação funda-se em três categorias: a generalidade, a particularidade e a singularidade. $\mathrm{O}$ ser humano estabelece vínculos tanto com a natureza, quanto com a sociedade por meio da relação dialética que se desenvolve entre seu ser singular, que não se assemelha a nenhum outro, e o seu ser geral, que se identifica com os outros seres humanos na vida em sociedade e com a espécie, bem como com todos os seres vivos na natureza. Assim, o ser humano é, ao mesmo tempo, portador de uma singularidade, que o distingue de todos os outros seres, e de uma generalidade que o torna um ser semelhante 
a qualquer outro: a relação dialética entre a diferença (singular) e a semelhança (geral) viabiliza a inserção do ser humano na natureza e na sociedade. Por isso, a singularidade e a generalidade, embora sejam estados do Ser, devem ser compreendidas no seu movimento de negação recíproca. O singular nega o geral, mas está presente nele e, por outro lado, a generalidade nega a singularidade, porém só se realiza por meio dela. A negação recíproca entre a singularidade e a generalidade é a particularidade; ela é o movimento que relaciona o singular com o geral.

A particularidade estabelece a mediação entre o singular e o geral; ela é responsável pela relação dos dois termos. Este movimento faz com que tanto a generalidade como a singularidade não sejam fixas; portanto, elas devem ser compreendidas como processos que tendem à generalização e à "singularização", respectivamente. Assim, não se pode alcançar a generalidade ou a singularidade, pois cada generalidade alcançada deve ser superada por uma outra que a contém. O mesmo ocorre com a singularidade; ela também deve ser entendida na perspectiva da superação.

Para Mészáros op cit., a mediação do homem com a natureza e os outros homens se configura como automediação:

A relação entre o homem e a natureza é 'automediadora' num duplo sentido. Primeiro, porque é a natureza que propicia a mediação entre si mesma e o homem; segundo, porque a própria atividade mediadora é apenas um atributo do homem, localizado numa parte específica da natureza. Assim, na atividade produtiva, sob o primeiro desses dois aspectos ontológicos, a natureza faz a mediação entre si mesma e a natureza; e, sob o segundo aspecto ontológico - em virtude do fato de ser a atividade produtiva inerentemente social - o homem faz a mediação entre si mesmo e os demais homens. (MÉSZÁROS, 1981, p. 77-78)

A automediação, de acordo com essa formulação, não exclui o homem da natureza, mas o distingue dela. Ele está localizado numa parte específica da natureza. Essa condição permite ao homem interferir nela. Nesse sentido, a natureza se auto-transforma, na medida em que o homem, agente da transformação, está inserido nela. É a natureza quem "propicia a mediação entre si mesma e o homem”, em primeiro lugar porque o homem é também natureza e em segundo lugar porque ela oferece as condições para que o ser humano a modifique. Por exemplo, o solo pode ser cultivado, o curso dos rios pode ser alterado, e os diamantes podem 
ser lapidados. Esse é o primeiro dos sentidos da automediação destacados por Mészáros, (op cit) o segundo diz respeito à mediação entre o homem e os outros homens que só se realiza por meio da atividade produtiva enquanto o modo pelo qual o ser humano transforma a natureza. Como os homens não se separam da natureza, as relações entre eles não podem se desenvolver fora dela. Por isso, na automediação se enfatiza o caráter ontológico da mediação. Dessa forma, demarca-se o cunho ontológico do trabalho docente.

\section{A ONTOLOGIA DO SER SOCIAL E O TRABALHO DOCENTE}

O segundo sentido da automediação, de acordo com Mészáros (op cit), é aquele que interessa quando se trata da discussão do trabalho docente na perspectiva da Ontologia do Ser Social. O trabalho desenvolvido pelo professor se expressa na relação entre ele e o aluno na aula. Em outras palavras, esta automediação só ocorre num contexto específico que é a aula. Embora o trabalho docente não se reduza à aula, é nela que se exprime o seu caráter ontológico. É na aula, e somente nela, que se estabelece a relação ontológica entre dois ou mais seres sociais que buscam ensinar ou aprender. Em uma relação ontológica, que é, necessariamente, dialética, eles não podem ensinar e aprender nem ao mesmo tempo nem de forma recíproca, porque desta maneira a tensão entre os dois pólos da relação de mediação professor e alunos - não pode desenvolver-se. Assim, para essa ontologia, o professor ensina e o aluno aprende. Isto ocorre porque o primeiro deve, necessariamente, estar no plano do mediato e o segundo no plano do imediato.

Cabe esclarecer que o imediato não é mais pobre nem inferior ao mediato, portanto, o mediato não é mais rico, melhor ou superior ao imediato; eles são estados distintos e opostos entre si. Dessa forma, as relações entre os estudantes e o professor não podem ser hierárquicas, nem de dominação por um lado ou de subordinação por outro. Elas devem pautar-se pelo esforço de mediação que não é nem automática nem espontânea. O que ocorre nas relações de mediação é que, como a tensão entre os pólos da relação é dinâmica, ora predomina um ora o outro. Assim, na relação estudantes — professor ora se evidencia a expressão do primeiro ora a do segundo. Cabe principalmente ao professor propiciar a expressão dos estudantes por meio da mediação. É preciso assinalar que, nessa concepção de mediação, professor e alunos serão sempre opostos entre si, porém não antagônicos. Por serem opostos, não há harmonia entre eles e, desse modo, não se pode esperar que desse confronto resulte um estado de equilíbrio. O esforço do professor, que está ou deveria estar, no plano do mediato, é o de trazer os estudantes para esse plano. Por outro lado, os estudantes, 
que quase sempre estão confortáveis no imediato, tentam trazer o professor para este campo. Neste jogo de forças, no qual ora os conflitos são velados ora são explícitos, é que se dá a mediação. Deste modo, os professores que valorizam as experiências cotidianas dos alunos e estimulam a sua reprodução, em nome das possibilidades da ocorrência de mediações, eliminam a "dialeticidade" da relação entre o imediato e o mediato, produzindo, assim, o efeito inverso, ou seja, dificultam ou impedem o desenvolvimento de mediações.

Cabe esclarecer que, para ensinar, o professor não pode ignorar o cotidiano dos estudantes, pois o ensino torna-se efetivo somente pela contraposição do conhecimento que ele pretende veicular a esse cotidiano. Mas, o professor não pode apropriar-se das vivências cotidianas dos estudantes, pois ele não é, e jamais poderá ser, um deles. Ao contrário disso, o docente deve empenhar-se por estabelecer as diferenças entre o conhecimento a ser difundido e as experiências cotidianas dos estudantes: quando enfatiza as diferenças entre os dois termos, o professor aborda as relações entre eles. Por outro lado, os estudantes aprendem quando relacionam, por meio da oposição, suas experiências cotidianas com os tópicos do conhecimento já sistematizado pela humanidade que lhes são apresentados pelo docente. Este conhecimento modifica a sua vida cotidiana, mas não a suprime, ao contrário, a fortalece, na medida em que permite que ela seja pensada e, dessa forma, articulada às experiências que a humanidade vem sistematizando no decorrer da história. Quanto maior esta articulação, maiores são as possibilidades de mediação entre os dois pólos. Isso explica porque se enfatizou a idéia de que o trabalho docente como automediação só pode ocorrer na aula. Em outros termos, a aula não pode reproduzir o cotidiano dos alunos, ao contrário, deve negá-lo para que o seu cunho imediato seja superado.

Cabe esclarecer que a aula compreende a mediação do professor com os alunos e vice-versa, ou seja, os alunos também medeiam com o professor sendo que nos dois casos, ocorre a superação do imediato - cotidiano dos alunos no mediato - conhecimento produzido pela humanidade que é selecionado, organizado e exposto pelo professor. O modo de exposição pode variar, mas, ela é fundamental para que ocorra a superação do imediato no mediato. Esta superação só é possível quando os estudantes têm a liberdade de confrontar as experiências cotidianas com o conhecimento sistematizado nas ciências e na filosofia. Este confronto torna-se mais explícito quando o aluno medeia com o professor, porém, esta mediação só ocorre quando o professor a estimula por meio das mediações que estabelece com os alunos. Quando o professor não se dispõe a desenvolver mediações ou não sabe como fazê-lo, os alunos não aprendem porque não podem, sozinhos, confrontar o seu cotidiano com 
o conhecimento. Ressalta-se que esta impossibilidade não é restrita aos alunos ela é inerente ao ser humano.

O fato de as categorias da Ontologia do Ser Social serem pouco usadas para explicar tanto o trabalho docente, não retira dele o seu cunho ontológico porque ele humaniza o ser humano. Caso isto não ocorre, não houve trabalho docente.

\section{CONCLUSÃO}

Neste texto, discutiu-se o fundamento ontológico do trabalho docente, com base na Ontologia do Ser Social, por meio da categoria mediação. A adoção dessa perspectiva teórica é possível porque a mediação é uma categoria de análise capaz tanto de explicar quanto de apresentar alternativas metodológicas para as práticas educativas, especialmente, quando se trata da atuação do professor na sua relação com o aluno.

Espera-se que este texto tenha mostrado as possibilidades do trabalho docente, quando compreendido ontológica e dialeticamente, no sentido de oferecer aos professores, alternativas de como relacionar-se com os estudantes respeitando a sua experiência cotidiana sem, contudo, atribuir a ela a possibilidade de fazer com que o estudante aprenda. O estudante só aprende por meio do confronto das suas experiências cotidianas com o conhecimento sistematizado pela humanidade. Este confronto, que é uma mediação, só pode ser organizado e estimulado pelo professor. Ele é quem inicia o processo de mediação.

Em suma, neste texto, sustenta-se que as mediações que se estabelecem entre docentes e estudantes constituem o trabalho docente.

\section{REFERÊNCIAS BIBLIOGRÁFICAS}

GARAUDY, R.. Para conhecer o pensamento de Hegel. ([Trad. Suely Bastos) Porto Alegre: L\&PM, 1983.

KOSIK, K. Dialética do Concreto. (Trad.Célia Neves e Alderico Turibio, 2. ed., Rio de Janeiro: Paz e Terra, 1976.

LEFEBVRE, H. Sociologia de Marx. (Trad. Carlos Roberto Alves Dias) Rio de Janeiro: Forense-Universitária, 1979. 
LEFEBVRE, H. La presencia y la ausencia. (Trad. Fondo Nacional de Cultura) México: Fondo Nacional de Cultura, 1983.

LUKÁCS, G. Ontologia do Ser Social: os princípios ontológicos fundamentais de Marx.

(Trad. Carlos Nelson Coutinho) São Paulo: Livraria Editora Ciências Humanas, 1979.

LUKÁCS, G. . Estética I. (Trad. Manuel Sacristán) México: Grijalbo, 1982.

MÉSZÁROS, I. Marx: a teoria da alienação. (Trad. Waltensir Dutra) Rio de Janeiro: Zahar, 1981. 